\title{
Assessment of awareness of pharmacy profession as a career among secondary school students in Kaduna state, Nigeria
}

\author{
Abbas Musa ${ }^{1,4}(\mathbb{D})$, Muhammad Garba Magaji² (D), Raliya Muhammad Bello ${ }^{3}($ \\ ${ }^{1}$ Department of Clinical Pharmacy and Pharmacy Management, Kaduna State University, Nigeria \\ 2 Department of Pharmacology and Therapeutics, Ahmadu Bello University, Zaria, Nigeria \\ ${ }^{3}$ Department of Educational Psychology and Counseling, Ahmadu Bello University, Zaria, Nigeria \\ ${ }^{4}$ Department of Clinical Pharmacy and Pharmacy Practice, Ahmadu Bello University, Zaria, Nigeria
}

\author{
Keywords \\ Career \\ Pharmacy \\ Profession \\ Secondary school \\ Correspondence \\ Abbas Musa \\ Department of Clinical Pharmacy and \\ Pharmacy Management \\ Faculty of Pharmaceutical Sciences \\ Kaduna State University \\ Nigeria \\ alpharmacyy@gmail.com
}

\begin{abstract}
Background: Pharmacists play prominent roles in the health care system and enjoy a wide variety of inter-related careers, placing them among the high-ranking health professionals. Aim: To assess the awareness of pharmacy as a career among secondary school students in the Zaria and Giwa educational zones of Kaduna State, Nigeria. Method: A cross-sectional survey was conducted in secondary schools located in the Zaria and Giwa educational zones in Kaduna state, Nigeria; a sample of 278 students completed a 26-item questionnaire. Results: The respondents displayed a fair knowledge of pharmacy (mean score of 9.8 out of 20), with significant differences in awareness observed between males and females $(p=0.026)$, students from private and public schools $(p<0.001)$, and those from schools located in urban and rural areas $(p<0.001)$. Conclusion: The students had a fair knowledge of pharmacy careers and pharmacists' roles and characteristics.
\end{abstract}

\section{Introduction}

The evolution of the pharmacy profession aims to meet the current healthcare needs of the people. To achieve this goal, the professional roles of pharmacists had shifted from product-oriented to patient-centred care in the form of pharmaceutical care (Ekpenyong et al., 2018). The pharmacy profession has a wide variety of career opportunities that include traditional practice areas, such as hospital, community, industry, academia, and administrative pharmacy (Ahmed et al., 2016; Kokane \& Avhad, 2016) and non-traditional practice areas, such as journalism, public health, veterinary, consultancy, information, and communication technology (Fink, 2005; Ubaka, Ochie, \& Adibe, 2013).

Pharmacists are experts in the science of drugs, including their chemistry, formulation into medicines, and use to manage diseases (Caroline \& MaCloskey, 2006). Pharmacists also play a critical role in the healthcare team (Iqbal, Jalees, Krishen, \& Sushama, 2008) by forming a professional relationship with other team members to achieve optimal health outcomes in the patient (Kehrer et al., 2013).

There is a low-level awareness about the role of pharmacists in the healthcare system in developing countries (Khan et al., 2013) due to their relatively low number and skewed distribution in such countries, including Nigeria (Ekpenyong et al., 2018). The public perceives pharmacy as a secondary profession to medicine and believes that most graduate pharmacists in developing countries joined pharmacy because of their inability to secure admission into their most preferred choices (Wilson et al., 2006; Modipa \& Dambisya, 2008; Beedemariam et al., 2014). The entry 
requirements for pharmacy candidates in Nigerian tertiary institution is similar to that of medicine, nursing, and many other healthcare-related disciplines (Ogaji \& Ojabo, 2014), making information about careers in pharmacy confusing.

Career choice is among the most critical decisions a secondary school student will make because of its long term implications. There is a strong relationship between vocational information and career choice (Baloch \& Shah, 2014). Indeed, most secondary school students in Nigeria have poor knowledge of pharmacists and the pharmacy profession (Ghazali et al., 2020). Lack of adequate or incorrect career information by students has been described as a primary factor leading to a wrong career decision, which, in most cases, results in an inability to satisfy the requirements of a particular career pathway, stagnation, disappointment, and development of unrealistic expectations (Baloch \& Shah, 2014; Wang'eri \& Karanja, 2018).

Assessing the level of awareness of pharmacy as a career and pharmacist roles and characteristics among secondary school students would provide stakeholders (policymakers, pharmacy associations, and pharmacy educators) the necessary tool to identify the categories of students requiring educational intervention to assist the students in making an informed decision regarding the choice of pharmacy profession as a career. Also, the findings from this research would provide information on the level of awareness of secondary school students before pursuing a career in pharmacy.

This study aims to assess the level of awareness of pharmacy as a career and the roles and characteristics of pharmacists among selected secondary school students in the Zaria and Giwa educational zones located in Kaduna State, Nigeria and compare the level of this awareness between students based on their demographic characteristics (age, gender, school type, and school location).

\section{Methods}

This cross-sectional survey is the first phase of a study assessing the impact of pharmacist intervention on knowledge and perception of pharmacy among secondary school students in the Zaria and Giwa educational zones, Kaduna State, Nigeria.

The data collection tool developed from literature (Aspden et al., 2015) is a 26-item questionnaire divided into two sections. Section A consisted of 12 questions: eight covered background information; the remaining four consisted of multiple-choice and open-ended questions designed to test the respondents' rudimentary knowledge of pharmacy entry requirements, pharmacists training, and pharmacy practice settings. Section B consisted of 14 questions relating to knowledge of pharmacist role and characteristics. The questionnaire was tested on 30 students from four different schools (two private and two public) located in both rural and urban areas within the educational zones of interest. These schools were excluded from the study.

\section{Study location}

The study was carried out in Kaduna State, located in northwestern Nigeria. The regulation of secondary school education is directly under the state government through the ministry of education, which has created twelve zonal offices across the 23 local governments of the state. These zonal offices are responsible for the direct supervision of the activities of both private and public secondary schools. Seven secondary schools located in the Zaria and Giwa educational zones of Kaduna State, Nigeria, were selected for the study. At the time the study was carried out, there were 305 senior secondary schools in the two zones. Zaria educational zone has 29 public and 124 private senior secondary schools, while Giwa educational zone has 17 public and 135 private senior secondary schools.

\section{Study participants}

Students in Nigeria are expected to undergo six years of primary education followed by six years in secondary school (three years in junior and another three in senior secondary school), and finally, tertiary education that varies from two to six years depending on the institution and course of study. In senior secondary schools, students are required to focus on a combination of subjects that will lead to a career in any of the sciences, humanities, or social sciences disciplines in tertiary institutions.

The participants comprised of science students in their second year in senior secondary school. The sample size was calculated using the formula put forward by (Yamane, 1967). The total sample consisted of 254 students, and a $10 \%$ attrition rate was added to reach 280 students.

\section{Study procedure}

Ethical approval was obtained from the ministry of education of Kaduna state, Nigeria, before starting data collection, then an introduction letter from the ministry was presented to the various schools involved in the study. The data were collected within the period of eight weeks (4 February 2019 to 1 April 2019). A brief 
introduction about the study was made, and verbal consent was soughed from the randomly selected participants, followed by the distribution of questionnaires by the researchers and eleven trained data collectors. Data collectors were trained by the researchers. The students were required to submit the filled questionnaires on the spot to ensure maximum return.

\section{Data analysis}

Data extracted from the questionnaire were coded and analysed using the statistical package for social sciences (SPSS version 20). The demographic information was presented as percentages, while the awareness of pharmacy career was quantified in the form of a knowledge score with a maximum of 20 . The maximum score of Section A was 6, while that of section B was 14 . Section $B$ was designed to contain a mixture of positive and negative questions. Students were expected to record their responses as YES, NO, or UNSURE. Nine statements were positive (i.e., "YES" as the correct answer), and five statements were negative (i.e., "NO" as the correct answer).

The level of awareness was assessed by categorising the scores obtained by the students into three categories, i.e. poor (less than 10 points), fair (10-13 points), and good (more than 14 points).

The Man-Whitney test was used to determine whether there was a statistically significant difference in perception between various variables. A value of $p<0.05$ was considered statistically significant.

\section{Results}

Out of the 280 estimated sample, 278 students participated, indicating a $99.3 \%$ return rate.

The majority of respondents were aged between 15-20 years (98.9\%), female students 166 (59.7\%), from public schools $234(84.2 \%)$, and from schools located in urban areas 177 (63.7) (Table I).

Table I: Background information of Respondents

\begin{tabular}{llc}
\hline Variables & & $\mathbf{n}(\%)$ \\
\hline Age (years) & $15-20$ & $275(98.9)$ \\
\multirow{2}{*}{ Gender } & $21-25$ & $3(1.1)$ \\
& Male & $166(59.7)$ \\
School type & Female & $112(40.3)$ \\
& Public & $234(84.2)$ \\
School location & Private & $44(15.8)$ \\
& Urban & $177(63.7)$ \\
& Rural & $101(36.3)$ \\
\hline
\end{tabular}

\section{Career choice options among students}

Of the total sample, 113 (40.6\%) students indicated that they would choose pharmacy as the most preferred career, while 103 (37.5\%) intend to study medicine (Table II).

Table II: Career choice options among students

\begin{tabular}{lc}
\hline Career option & $\mathbf{n}(\%)$ \\
\hline Pharmacy & $113(40.6)$ \\
Medicine & $103(37.1)$ \\
Others* & $62(22.3)$
\end{tabular}

*Others: Nursing 18 (6.5\%), Engineering 15 (5.4\%), Armed forces 4 (1.4\%), Teaching 3 (1.1\%), Architecture 6 (2.2\%), Agriculture 7 (2.5\%), Computer science $9(3.2 \%)$

\section{Awareness of entry requirements, pharmacists training institution, and minimum study duration for Bachelor of pharmacy}

The majority of respondents, 185 (66.5\%), were aware of the five ordinary level subject required in pharmacy, while 216 (77.7\%) and 215 (77.3\%) were not aware of the correct pharmacists training institution and how long it takes to study Bachelor of pharmacy through Joint Admissions and Matricular Board (JAMB), respectively (Table III).

Table III: General awareness of entry requirement, institutions where pharmacists are trained and minimum duration of study for Bachelor of pharmacy

\begin{tabular}{lcc}
\hline Question & \multicolumn{2}{c}{ Responses } \\
& Correct & Wrong \\
\hline $\begin{array}{l}\text { Five ordinary level subjects } \\
\text { required in Pharmacy }\end{array}$ & $185(66.5)$ & $93(33.5)$ \\
$\begin{array}{l}\text { The institution where pharmacists } \\
\text { are trained }\end{array}$ & $62(22.3)$ & $216(77.7)$ \\
$\begin{array}{l}\text { Duration of study through UTME* } \\
\text { *UTME: Unified Tertiary Matriculation Examination }\end{array}$ & \\
\end{tabular}

\section{Awareness of pharmacy practice settings}

About one-third, 103 (37.1\%), was able to identify at least two settings where pharmacists could work (Table IV).

Table IV: Students awareness of at most three practice settings

\begin{tabular}{lc}
\hline Responses & $\mathbf{n}(\%)$ \\
\hline All three are wrong & $90(32.4)$ \\
Only one is correct & $85(30.6)$ \\
Only two were correct & $77(27.7)$ \\
All three were correct & $26(9.4)$ \\
\hline
\end{tabular}




\section{Awareness of pharmacists' roles and characteristics}

Respondents were required to respond to knowledge questions regarding pharmacists and the pharmacy profession (Table V). The questions answered correctly by the students were: 'Pharmacists are trained to prepare, mix, and dispense medicines and provide information on the use of medicines/health products and herbal medicines' 249 (89.6\%), 'Pharmacists are involved in the sale of medical and surgical aids and other health products' 217 (78.1\%), 'Pharmacists can be involved in the design and manufacture of medicines' 226 (81.3\%), 'Pharmacists can be involved in the design and manufacture of medicines' 226 (81.3\%).

Table V: Students responses to various knowledge statements regarding pharmacists' roles and characteristics

\begin{tabular}{|c|c|c|}
\hline Statements & \multicolumn{2}{|c|}{ Responses } \\
\hline & Correct & Wrong \\
\hline 1. One year internship training is not necessary for graduate pharmacists ${ }^{*}$ & $48(17.3)$ & $230(82.7)$ \\
\hline $\begin{array}{l}\text { 2. Pharmacists are trained to prepare, mix and dispense medicines and provide } \\
\text { information on the use of medicines/health products and herbal medicines }{ }^{* *}\end{array}$ & $249(89.6)$ & $29(10.4)$ \\
\hline 3. Once registered, a pharmacist does not need to undertake any further training ${ }^{*}$ & $133(47.8)$ & $145(52.2)$ \\
\hline $\begin{array}{l}\text { 4. Pharmacists are involved in the sale of medical and surgical aids and other health } \\
\text { products** }\end{array}$ & $217(78.1)$ & $61(21.9)$ \\
\hline 5. Pharmacists spend most of their time in the dispensary counting tablets ${ }^{*}$ & $87(31.3)$ & $191(68.7)$ \\
\hline 6. Pharmacists, pharmacologists, and nurses have the same job description* & $83(30)$ & $194(70)$ \\
\hline 7. Pharmacists can be involved in the design and manufacture of medicines** & $226(81.3)$ & $52(18.7)$ \\
\hline $\begin{array}{l}\text { 8. Pharmacists can provide services such as blood pressure measurement and glucose } \\
\text { testing** }\end{array}$ & $182(65.5)$ & $96(34.5)$ \\
\hline 9. Pharmacists can participate in hospital ward rounds** & $176(63.3)$ & $102(36.7)$ \\
\hline 10. Pharmacists can work as a professional in the armed forces and veterinary hospitals ${ }^{* *}$ & $140(50.4)$ & $137(49.3)$ \\
\hline 11. Pharmacists are trained to be bankers ${ }^{*}$ & $204(73.4)$ & $74(26.6)$ \\
\hline 12. Pharmacists can provide professional roles in the oil and gas, and Aviation sector** & $73(26.3)$ & $205(73.7)$ \\
\hline 13. Pharmacists can work in agencies like NAFDAC ${ }^{a}, \mathrm{WHO}^{\mathrm{b}}{ }^{* *}$ & $206(74.1)$ & $72(25.9)$ \\
\hline 14. Pharmacists can work as a professional in the media sector ${ }^{* *}$ & $71(25.5)$ & $207(74.5)$ \\
\hline
\end{tabular}

\section{Assessment of students' level of awareness}

The majority of students had a fair level of awareness of pharmacy as a career, 142 (51.1\%) (Table VI).

Table VI: Assessment of students level of knowledge of careers in pharmacy and pharmacist roles

\begin{tabular}{lcc}
\hline Level of knowledge & Frequency & Percentage \\
\hline Poor $(<10)$ & 121 & 43.5 \\
Fair $(\mathbf{1 0 - 1 3 )}$ & 142 & 51.1 \\
Good $(\geq 14)$ & 15 & 5.4 \\
\hline
\end{tabular}

\section{Knowledge scores of students in relation to the independent variables}

The overall mean pharmacy awareness score obtained was 9.80 out of 20. Significant differences were obtained between students' awareness scores $(p<0.05)$ (Table VII). Significantly higher knowledge scores were found in male vs female students $(p=0.026)$, private school students vs their public counterparts, students from schools located in urban areas vs those in rural areas $(p<0.01)$, and students who intended to choose pharmacy as a preferred career choice compared to those interested in other disciplines $(p=0.007)$.

\section{Discussion}

The proportion of students interested in studying pharmacy was significantly higher than what was reported among secondary school students in Lagos (Ghazali et al., 2020). This result could be due to differences in the level of awareness of careers in pharmacy and the demographic characteristics of the various respondents.

This study's findings revealed that the majority of the respondents seemed to be knowledgeable about the minimum entry requirements in senior secondary school certificate examinations, different from what was reported by Lawer in 2007, as cited by Ampofo (2020). This result was expected because all the respondents were science students, and pharmacy entry requirements are the same as those of medicine and nursing. 
Table VII: Assessment of pre-intervention knowledge of pharmacy across independent variables

\begin{tabular}{|c|c|c|c|c|c|c|}
\hline Variable & $\mathbf{n}$ & Mean score & Median & $U$-statistic & z-score & $p$-value* \\
\hline \multicolumn{7}{|c|}{ Age(years) } \\
\hline $15-20$ & 275 & 9.80 & 10.00 & & & 0.421 \\
\hline $21-25$ & 3 & 9.00 & 9.00 & 302.00 & -0.805 & \\
\hline \multicolumn{7}{|l|}{ Gender } \\
\hline Female & 166 & 9.51 & 10.00 & & & 0.026 \\
\hline Male & 112 & 10.21 & 10.00 & 7844.00 & -2.228 & \\
\hline \multicolumn{7}{|c|}{ School type } \\
\hline Public & 234 & 9.51 & 10.00 & & & $<.001$ \\
\hline Private & 44 & 11.30 & 11.00 & 2875.50 & -4.686 & \\
\hline \multicolumn{7}{|c|}{ School location } \\
\hline Urban & 177 & 10.44 & 10.00 & & & $<.001$ \\
\hline Rural & 101 & 8.66 & 9.00 & 5025.00 & -6.124 & \\
\hline \multicolumn{7}{|c|}{ Pharmacy as an ideal choice } \\
\hline No & 165 & 9.33 & 10.00 & & & 0.007 \\
\hline Yes & 113 & 10.11 & 9.00 & 7560.00 & -2.701 & \\
\hline \multicolumn{7}{|c|}{ Related to a pharmacist } \\
\hline No & 175 & 10.02 & 10.00 & & & 0.07 \\
\hline Yes & 102 & 9.63 & 10.00 & 7771.00 & -1.810 & \\
\hline
\end{tabular}

The majority of students were not able to identify the institutions where pharmacists are trained, consistent with the findings of Lawer in 2007, as cited by Ampofo (2020), where the majority of respondents were not aware of training required for employment in various career pathways. The reason could be the proliferation of technician training institutions in the country and the ease of admission to these institutions.

Most respondents were not aware of the minimum training duration for pharmacists, likely due to the closeness of pharmacy to medicine and the mandatory one-year internship program pharmacists complete before acquiring a practising license (Ogaji \& Ojabo, 2014).

This study's results also revealed that most students had inadequate knowledge of pharmacy practice areas, consistent with previous findings from Lagos (Ghazali et al., 2020). A possible explanation could be the considerable number of students who intend to choose medicine as their preferred choice, the relatively lower number of practising pharmacists in northern Nigeria (Ekpenyong et al., 2018), and the low number of pharmacists compared to other health professionals.

Most students had also indicated a lack of awareness of further training the pharmacists should undergo, such as internships and mandatory continuous professional development. This kind of information may not be readily available except for senior pharmacists that had at least practised for a minimum of five years, and students may hardly come in contact with them (Ogaji \& Ojabo, 2014).
The majority of students were aware of the roles pharmacists play in hospital and community pharmacy settings, likely because most pharmacists in Nigeria practise in one of these settings (Ekpenyong et al., 2018). Also, it was reported that community and hospital pharmacy settings are the most preferred areas of practice among pharmacy students (Hanna, Askin \& Hall, 2016; Alhaddad, 2018).

Awareness of pharmaceutical jobs in non-traditional pharmacy practice settings tends to be low among students. The reason could be the low number of pharmacists practising in these areas compared to the number in traditional settings (Ekpenyong et al., 2018) and that these jobs, in many instances, are taken by non-pharmacists.

Male students had better awareness of the pharmacy profession than female students in this study, likely due to factors such as having more access to career information (Hamatuli, n.d.; Zafar, 2019), better academic performance in secondary school, and more motivation to pursue higher education than females in Northern Nigeria (Musa, 2013).

This study's findings revealed that students from private schools had better knowledge scores than their counterparts from public schools, consistent with the results of other researchers (Adeyemi, 2014). The reason could be the better supervision and equipment for both teaching and learning in private schools (Alimi, Ehinola \& Alabi, 2012).

Students from schools located in urban areas had a better awareness of the pharmacy profession than 
those from rural schools. This result could be due to the better access to career information (Hamatuli, n.d.) and the fact that students from urban areas are more likely to encounter a pharmacist than their rural counterparts (Ekpenyong et al., 2018).

The study limitations include the following: the study was conducted in one state in Nigeria and may not be generalisable, but the two educational zones have the highest number of secondary school students, and Kaduna state is among the most populous and diverse states in Nigeria.

\section{Conclusion}

The students had a fair knowledge of careers in pharmacy and pharmacists' roles and characteristics. The awareness is influenced by student gender, school location, and the type of school. Awareness campaigns by pharmacy associations are recommended to improve the knowledge of the pharmacy profession, particularly among students from rural areas. Also, further research is warranted to determine whether the willingness to choose pharmacy as a career will translate into an actual choice of pharmacy in the future.

\section{References}

Adeyemi, S. B. (2014). Comparative Study of Pupils' Academic Performance between Private and Public Primary Schools. World Journal of Education, 4(4). Sciedu Press. https://doi.org/10.5430/wje.v4n4p55

Ahmed, Ibrahim Fathelrahman Mohamed, I. M. I., \& Wertheimer, A. I. (2016). Pharmacy practice in Nigeria. In A. I. Fathelrahman \& A. I. Wertheimer (Eds.), Pharmacy practice in Developing countries: Achievement and Challenges (pp. xxix-xxxix). London: Elsevier B.V

Alhaddad, M. S. (2018). Undergraduate pharmacy students' motivations, satisfaction levels, and future career plans. Journal of Taibah University Medical Sciences, 13(3), 247253. Elsevier Ltd.

https://doi.org/10.1016/j.jtumed.2018.03.004

Alimi, O. S., Ehinola, G. B., \& Alabi, F. O. (2012). School types, facilities and academic performance of students in senior secondary schools in Ondo State, Nigeria. International Education Studies, 5(3), 44-48. https://doi.org/10.5539/ies.v5n3p44

Ampofo, J. A. (2020). Career choices of senior high technical students in the Wa municipality of Ghana. International Journal of Applied Research in Social Sciences, 2(5), 111129. Fair East Publishers.

https://doi.org/10.51594/ijarss.v2i5.175
Aspden, T., Cooper, R., Liu, Y., Marowa, M., Rubio, C., Waterhouse, E. J., \& Sheridan, J. (2015). What secondary school career advisors in New Zealand Know about pharmacy and how that knowledge affects student career choices. American journal of pharmaceutical education, 79(1), 1-8. https://doi.org/10.5688/ajpe79107

Baloch, R., \& Shah, N. (2014). The significance of awareness about selection and recruitment processes in students' career decision making. European Scientific Journal, 10(14), 1857-7881

Beedemariam, G., Ebro, M., \& Ageze, H. (2014). Pharmacy Students' Attitude and Future Career Choices: A survey of Four Public Schools of Pharmacy in Ethiopia. Ethiopian Pharmaceutical Journal, 30(1), 57-63. https://doi.org/10.4314/epj.v30i1.6

Caroline, S. Z., \& MaCloskey, W. (2006). Pharmacists' Role in the Healthcare System. Harvard Health Policy Review. Retrieved September 28, 2020, from https://www.researchgate.net/publication/235418627_Pha rmacists'_Role_in_the_Healthcare_System

Ekpenyong, A., Udoh, A., Kpokiri, E., \& Bates, I. (2018). An analysis of pharmacy workforce capacity in Nigeria.. Journal of Pharmaceutical Policy and Practice, 11(1). https://doi.org/10.1186/s40545-018-0147-9

Fink, L. J. (2005). Scope of Pharmacy. In T. David (Ed.), Remington The science and practice of pharmacy (21st ed., pp. 3-6). Baltimore: Lippincott Williams \& Wikkins

Ghazali, Y., Okeke, A., \& Okoya, F. (2020). Impact assessment of pharmacy awareness campaigns conducted in selected high schools across Lagos, Nigeria. Heliyon, 6(7), 1-5. Elsevier Ltd.

https://doi.org/10.1016/j.heliyon.2020.e04380

Hamatuli, P. F. (n.d.). Careers information provision in secondary schools of Zambia. Retrieved from https://www.academia.edu/7295008/Careers_information_ provision_in_secondary_schools_of_Zambia

Hanna, L. A., Askin, F., \& Hall, M. (2016). First-year pharmacy students' views on their chosen professional career. American Journal of Pharmaceutical Education, 80(9). https://doi.org/10.5688/ajpe809150

Iqbal, Z., Jalees, A. F., Krishen, K. R., \& Sushama, T. (2008). Pharmacist as an indispensable part of health care system: $A$ survey, outcome and reflections. Indian Journal of Pharmaceutical Education and Research, 42(1), 78-83

Kehrer, J. P., Eberhart, G., Wing, M., \& Horon, K. (2013). Pharmacy's role in a modern health continuum. Canadian Pharmacists Journal, 146(6), 321-324. Canadian Pharmacists Association.

https://doi.org/10.1177/1715163513506370

Khan, M. U., Khan, A. N., Ahmed, F. R., Feroz, Z., Rizvi, S. A., Shah, S., Hussain, R., et al. (2013). Patients' opinion of pharmacists and their roles in the health care system in Pakistan. Journal of Young Pharmacists, 5(3), 90-94. No longer published by Elsevier.

https://doi.org/10.1016/j.jyp.2013.08.001 
Kokane, J. V, \& Avhad, P. S. (2016). Role of Pharmacist in Health Care System. The Journal of Community Health Management, 3(1), 37

Modipa, S. I., \& Dambisya, Y. M. (2008). Profile and career preferences of pharmacy students at the University of Limpopo, Turfloop Campus, South Africa. Education for health (Abingdon, England), 21(3), 164

Musa, A. (2013). Gender, geographic locations, achievement goals and academic performance of secondary school students from Borno State, Nigeria. Research in Education, 90(1), 15-31. https://doi.org/10.7227/RIE.90.1.2

Ogaji, J. I., \& Ojabo, C. E. (2014). Pharmacy education in Nigeria: The journey so far. Arch Pharma Pract, 5(2), 47-60. https://doi.org/10.4103/2045-080X.132644

Ubaka, C. M., Ochie, U. M., \& Adibe, M. O. (2013). Student pharmacists' career choices: A survey of three Nigerian schools of pharmacy. Pharmacy Practice, 11(3), 149-155. https://doi.org/10.4321/S1886-36552013000300005

Wang'eri, T., \& Karanja, R. N. (2018). Extent Of Students' Knowledge Of Their Personality Traits, And Career Information In Career Aspirations Among Secondary School Students In Kiambu County, Kenya. International Journal of Innovative Research and Advanced Studies (IJIRAS), 5(5), 6170

Wilson K, Jesson J, Langley C, H. K. and C. L. (2006).

Pharmacy undergraduate students: career choices and expectations across a 4-year degree program

Yamane, T. (1967). Statistics, an Introductory Analysis. Journal of the American Statistical Association, 60(310), 678. JSTOR. https://doi.org/10.2307/2282703

Zafar, M. (2019). Career Guidance in Career Planning among Secondary School Students. Asian Journal of Education and Social Studies, 5(1), 1-8. Science domain International. https://doi.org/10.9734/ajess/2019/v5i130133 